\title{
IN-SITU IMPURITY MEASUREMENTS \\ IN PDX EDGE PLASMA
}

\author{
BY
}

MASTER

P. STAIB, H. F, DYLLA,

AND $S, M$, ROSSINAGEL

\section{PLASMA PHYSICS LABORATORY}

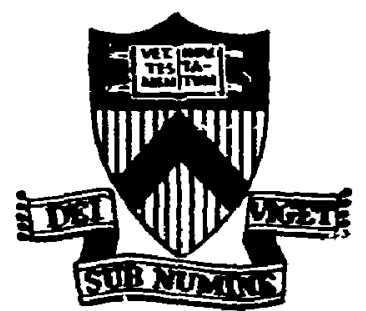

Heutron of rans docingent is Ulighited

\section{PRINCETON UNIVERSITY PRINCETON, NEW JERSEY}

This work was supporied by the J.s. Department of Energy Contract No. DE-ACO2-:E-CHC 3073, Reproduc:ion, translation, fublication, use anc disoosa:, it, whole ar in part, by or for the Unized States government is permitied. 
IN-SITU TMPURITY MEASUREMENTS IN PDX EDGE PLASMA

Ph. Staib, H. F. Dylla, S. M. Rossnagel

\begin{abstract}
The surface analysis station on PDX combines several surface analysis techniques (AES, XPS, SIMS) for in-situ measurement of impurity fluxes in the edge-plasma. The major impurities deposited on a sample surface during nondiverted PDX discharges are oxygen, titanium (limiter material) and chlorine. The impurity fluxes measured at different radial positions decreased by a factor of ten from the plasma edge to the wa]1. The sample surface collecting the impurity ions is located behind a circular aperture, The observed broadening of the deposition profile of Ti relative to the aperture diameter enables an estimate to be made of the ratio of charge state/energy of $T i$ ions in the edge plasma. Time-resolved analyses of the deposited impurities are presented which indicate that the time behavior for varj-us impurities may be quite different for different impurity species. This aspect is discussed in relation to probable impurity release mechanisms.
\end{abstract}




\section{INTRODUCTION}

The use of surface probes combined with in- situ surface analyses has been applied to the analysis of impurities in the edge region of many tokamak plasmas [1-5]. The method consists of exposing a sample surface of known composition in the scrape-off layer and measuring the resulting surface modifications. The number of atoms deposited (or removed) is measured and from this quantity the impurity flux to the surface (or erosion rates) can be inferred [2]. Such investigations can be performed far from the plasma-edge, a region which is not accessible to the standard plasma impurity dlagnostics. For divertor experiments like PDX, ASDEX or DITE, these investigations are of central importance because they allow a quantitative comparison between normal and diverted scrape-off layer conditions.

The results presented in this contribution are concerned with the characterization of circular plasma discharges in the Poloidal Divertor Experiment (PDX) in its predivertor phase. The total impurity fluxes and their dependence with the sample radial position are presented in section 3 . The sample surfaces are exposed behind diaphragms and the resulting energy dependent transmission of the ion fluxes tinrough such holes is discussed in Section 4. Tiue resolved measurements of the impurity fluxes are presented in Sestion 5. The time behavior is shown to vary considerably for similar plasma conditions, and this aspect is discussed in section 6 in the light of possible impurity release mechanisms.

\section{EXPERIMENTAL CONDITIONS}

The Surface Analysis station (SAS) allows samples to be exposed in the edge-plasma of PDX and allows in-situ analysis after exposure using combined surface analysis techniques [6]. Auger Electron Spectroscopy (AES), X-ray Photoelectron Spectroscopy (XPS), and Secondary Ion Mass Spectrometry (SIMS) 
are combined surface diagnostics giving not only the elementary surface composition (AES), but als: indications of the chemical state (XPS) and evidence for molecule formation (SIMS). The sample is a stainless steel tape which travels from the LHV analysis chamber where AES, XPS and sIMS are performed, through a preparation section for evaporation, glow-discharge cleaning and gas exposure, into the PDX vacuum vessel. The samples are exposed in the POX scrape-off layer behind two $3.8 \mathrm{~mm}$ diameter holes in an aluninum shield. The holes face in opposite directions cf the toroidal magnetic field. Time-resolved analyse: are obtained by moving the tape behind the holes during the discharge.

The radial position of the SAS sample can be adjusted by moving the whole SAs system on rails. The ilasma radius in the non-diverted configuration is determined by the upper and lower limiters $\left(a_{L}=50 \mathrm{~cm}\right.$ ) rather than by the outside-inside limiters (at $55 \mathrm{~cm}$ ). The limiters are made of titanium and are located at a toroidal angular distance of $160^{\circ}$ from the SAS position. The vacuum chamber wall is located at a radius of $66 \mathrm{~cm}$ from the plasma center and is made of stainiess steel. The sas sample distance to the "plasma boundary" is not known accurately because it depends on the position of the plasma column during a discharge.

The typical paraneters of the plasma discharges (non-diverted) studied in this paper are $B_{T}=1.7 \mathrm{~T}, I_{p}=300 \mathrm{kA}, t_{D}=400-800 \mathrm{ks}, n_{e}=0.8-1.5$ $\times 10^{13} \mathrm{~cm}^{-3}, v_{\text {Loop }}=1.5 \mathrm{v}, \mathrm{kT}_{\mathrm{e}}(0) \leq 1.2 \mathrm{keV}$ and $\mathrm{kT}_{i} \leq 700 \mathrm{eV}$. The fill gas was hydrogen [7].

\section{IMPURITY FLUXES DURING HIGH POWER DISCHARGES (HPD)}

According to the orientation of the apertures, the particle fluxes parallel and antiparallel to the toroidal field direction are measured $\Gamma_{\|}$. The major inpurites detected are $0, \mathrm{Ti}, \mathrm{Fe}, \mathrm{Cr}, \mathrm{Cl}, \mathrm{S}$ and $\mathrm{N}$. 
The flux values at various radial positions are given in Fig. 1. These values are obtained either from integrated exposures, i.e., with the tape remaining in a fixed fosition during the discharge, or from time-resolved exposures, after integration over the discharge time. Both methods lead to similar values for the fluxes and demonstrate that the calibration by AES is correct: The Auger electron emission is proportional to the number of atoms only for thin atomic layers, less than $3 \times 10^{15}$ atoms $\mathrm{cm}^{-2}$. Ar higher surface densities, the signal reaches a saturation value, saturation behavior has been experimental.Iy observed by comparing the atomic densities obtained for an increasing number of discharges. In the present case, care was taken to overlap a small number of dischaxges ( 13$)$. For time-resolved analyses the densities are as $10 \mathrm{w}$ as a few $10^{13}$ atoms $\mathrm{cm}^{-2}$, far below the saturation threshold.

We observe an increase by a factor of ten of the fluxes for exposures close to the wall dompared to near the plasma. Assuming an exponential decay over this range, the e- folding distance is $\delta=4 \mathrm{~cm}$. For comparison, the fluxes of different limiter materials measured close to the plasma and close to the wall are given in Table 1 for different tokamaks. Data obtained on ASDEX [8] are similar to those of PDX except that the fluxes for stainless steel cunstituents (Ee, $C r, M i$ ) are Larger, but this situation may evolve as the ASDEX machine becomes sleaner. The limiter material fluxes (Inconel alloy, mainly Ni) in TFR 600 are considerably higher [9] even during highdensity discharges. Also indicated in Table 1 are flux measurements from TFR 400 because the lowest $\delta$ values are found $[10,11]$. It appears that the e-folding distances are proportional to the safety distance (D) between plasma-edge and wall $\delta=D / 3$. 
The titanium flux near the wall in EDX is perceptible, 1 to $3 \times 10^{13}$ atoms $\mathrm{cm}^{-2} \mathrm{~s}^{-1}$. This means that after roughly 300 discharges one monolayer of limiter material has been spread over the wall surface. This layer has been shown to be completely oxidized [12].

\section{DEPOSITION PROEILE BEHIND THE APERTURE}

A collectox placed behind an aperture will measure lower ion fluxes than a collector directly exposed, for the case where the mean gyration radi $i$ of the ions are comparable or larger than the size of the aperture. Furthermore, the shape of the deposit gives information on the ion energy and charge state $[2,13]$. In the present case, the apertures are circular holes, $0.38 \mathrm{~cm}$ in diameter, in a thin $(0.01 \mathrm{~cm})$ sheet. Using these boundary conditions the flux deposited at a distance $\mathbf{x}$ from the hole center is calculated using the general procedure given in [14].

An isotropic velocity and a Maxwellian energy distribution are assumed. The flat top of the measured deposition profile (Fig. 2) shows that the flux at the center is not noticeably limiteo by the aperture. The profile for titanium is consistent with a distribution of $\mathrm{Ti}^{+}(\mathrm{kT}=4 \mathrm{eV})$ ions, or with higher charge states such as $\mathrm{Ti}^{2+}(16 \mathrm{eV}), \mathrm{Ti}^{3+}(36 \mathrm{eV})$, etc. Because the limiter is located far from the collector, the ions have to travel a long distance in the scrape-off region. This is not presently measured, but assuming $\mathrm{kr}_{\mathrm{e}} \approx 50 \mathrm{eV}$, the $\mathrm{Ti}^{4+}$ state would be expected and the ion temperature is $\sim 64 \mathrm{eV}$. Similar conclusions are drawn from the analysis of Fe in the PLT edge plasma [5], and from analysis of Ni in TFR 600 edge plasma [9, 13]. In the latter study, different boundary conditions (thick wall hole geometry) and a correspondingly modified theoretical model were used. 


\section{TIME-RESOLVER MEASUREMESIIS}

Time-resolved flukes are obtained by moving the tape during the discharge. The time resolution is about $70 \mathrm{~ms}$ and is determined by the tape speed and aperture diame:ter. The effect of the broadening of the distribution behing the hole on the resolution can be neglected, and the aperture is large enough to avoid an energy dependent flux correction. Because the atom flux to the surface leads to a quite low surface coverage $\left(\sim 10^{-2}\right.$ monolayers $), a$ few plasma discharges are overlayed (2 to 4$)$. The apercure arrangement in the SAS [6] allows two distributions to be obtained, corresponding to the sample orientations parallel or antiparallel to the plasma current (designated as the ion-drift and electron drift directions).

For the PDX exposures the impurities measured were $0, C_{I}$ and $T i$, and these fluxes were calibrated. A new ExB-analyzer was used at the same time to measure the hydrogen ion flux [14] and some results are included. For similar plasma discharge parameters, differing impurity behavior has been observed. A first kind of discharge is shown in Fig. 3. The ion and electron drift side distributions are given and are very similar except for $T i$, for which the Elux on the ion-drift side is nearly two times higher than on the electrun drift side. This kind of discharge is characterized by the observation that all impurity fluxes have similar time behavior according to the scheme: increase, then plateau, then peak at the discharge termination. The $\mathrm{H}^{+}$fIux, measured with the ExB-analyzer probing the ion-drift side at the same radial distance to the plasma, shows a similar behavior except that we observe well-developed sharp peaks at the beginning. The time constants of both devices are very different (2 ms for the $E \times B$ and $70 \mathrm{~ms}$ for the SAS), and unresolved peaks in the impurity flux may also exist at the beginning of the discharge. 
The other kind of discharge that was observed is shown in Fig. 4. The time behavior of the fluxes differ noticeably for different impurities. Whereas $\mathrm{T} i$ has a peak at the beginning followed by a plateau, $\mathrm{Cl}$ and o have a more complex time dependence with an absence of a plateau and a strong peak at the beginning followed by a lower flux plateau region and a modest increase at the end. The $\mathrm{H}^{+}$Elux shows a strong peak at the beginning followed by a lower flux plateau region and a modest increase at the end. This dependence is similar to that of titanium.

The flux values in the plateau region of the discharge are lower than the values Found for time-integrated exposures. At a distance of $20 \mathrm{~mm}$ behind the limiter radius, the plateau values are Ti: 1 to $2 \times 10^{14}, 0: 5$ to $10^{14} 10^{14}$, and $\mathrm{Cl}$ : 2 to $4 \times 10^{14}$ atoms $\mathrm{cm}^{-2} \mathrm{~s}^{-1}$.

\section{DISCUSSION}

The different mechanisms able to release impurities from the inner surface of a tokanak vacuum vessel have been recognized [1-5] and are studied in some cases with great detail. The question of their relative contrikution to plasma impurity contenc is still open because of the complicated problem of impurity transport in the edge-plasma. Definitive results have not been reached, partly because some important parameters such as charge state, temperature and density of the impurities in the scrape-off layer are not known, and further, because the high complexity of the wall surface (oxides, hydroxides, hydrocarbons) makes every estimate based on atomic data of questionable accuracy. In this context, the presented time-resolver measurements show that impurity fluxes can have either a similar time dependence, or each impurity may follow a quite different time behavior. The Eirst case could be understood as the result of sputtering or melting, because the impurity fluxes are proportional to the hydrogen flux. This 
interpretation cannot hold for the second case which is more complex in detail. This situation supports the supposition that several impurity production mechanisms have to be invoked at different times of the discharge. ACKNOFLEUGMENTS

The authors wish to thank S. A. Cohen, D. M. Meade, and K. Bol Eor scientific and moral support, and thank R. Noore, T. Provost, and the PDX crew for technical assistance. This work was supported by the U.S. Department of Energy Contract No. DE-AC02-76-CHO-3070. 


\section{REFERENCES}

[1] G. M. McCracken and P. E. Stott, Nucl. Eusion 19 (1979) 889.

[2] S. A. Cohen, J. Nucl. Mat. $76-77$ (1978) 68 .

[3] Ph. Staib and G. Staudenmaier, J. Nucl. Mat. $\underline{76-77}$ (1978) 78.

[4] R. Behrisch, J. Nucl. Mat. $85-86$ (1979) 1047.

[5] S. A. Cohen and H. F. Dylla, J. Nucl. Mat. $\underline{76-77}$ (1978).

[6] S. M. Rossnagel, H. F. Dylla and Ph. Staib, to be published.

[7] D. K. Owerss, et al., 4th International Conference on Plasma - Surface Interactions in Controlled Fusion Devices (Garmisch-Partenkirchen, E.R.G., April 1980) paper D-1.

[8] Ph. Staib, G. Staudenmajer and B.M.U. Scherzer, unpublished.

[9] G. Staudenmaier and Ph. Staib, 4th International conference on PlasmaSurface Interactions in Controlled Fusion Devices (GarmischPartenkirchen, F.R.G., April 1980) paper A-3.

[10] G. Staudenmaier, Ph. Staib and G. Venus, J. Nucl. Mat 76-77 (1978) 445.

[11] Equipe de TER, Proc. Int. Symp. on Rlasma-wall Interactions, Julich, Oct. 1976, CEC Report (1977) p. 3.

[12] Ph. Staib, S. M. Rossnagel and H. F. Dylla, J. Vac. Sci. Technol. 17 (1980) 291.

[13] G. Staudenmaier and Ph. Staib, Bull. Amer. Phys. Soc. 24 (1979) 1004.

[14] Ph. Staib, 4th international Conference on plasma Surface Interactions in Controlled Fusion Devices (Garmisch-Partenkirchen, F.R.G., April 1980) paper $G-1$.

[15] H. F. Dylla and S. A. Cohen, J. Nucl. Mat. 63 (1976). 
TABLE 1

\begin{tabular}{|c|c|c|c|c|c|}
\hline & $\begin{array}{l}\text { Limiter } \\
\text { Material }\end{array}$ & $\begin{array}{l}\Gamma_{\text {I }}\left(10^{14} \text { ato }\right. \\
\text { near } \\
\text { plasma edge }\end{array}$ & $\begin{array}{l}-\mathbf{s}^{-1} \text { ) } \\
\text { near } \\
\text { wall }\end{array}$ & $\begin{array}{l}\delta \\
(\mathrm{cm})\end{array}$ & $\begin{array}{l}\text { D, } \\
\text { distance } \\
\text { piasma } \\
\text { edge to } \\
\text { wall }(\mathrm{cm})\end{array}$ \\
\hline PDX & $\mathrm{Ti}$ & 3 & 0.3 & 4 & 11 \\
\hline ASDEX & S. S. & 7 & 0.8 & $5-6$ & 16 \\
\hline TFR 600 & $\begin{array}{l}\text { Inconel } \\
\text { (Ni) }\end{array}$ & 250 & 80 & 2.5 & 6 \\
\hline TER 400 & Mo & 10 & 0.4 & 0.5 & 1.5 \\
\hline
\end{tabular}

Comparison of the limiter material fluxes, e-folding distance (S) and geometrical width (D) of the edge-plasma region for different tokamaks. 

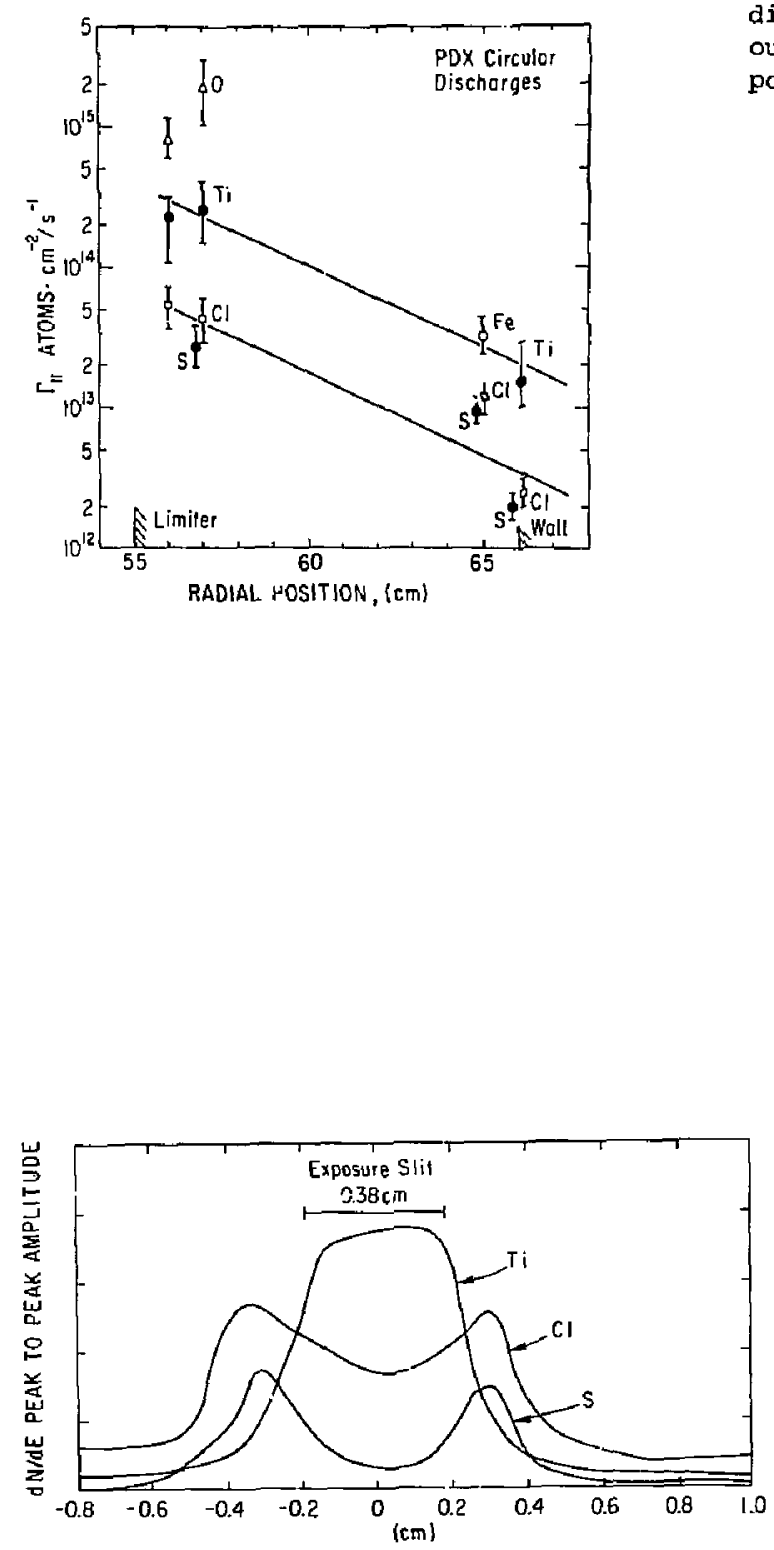

(PPPL-803496)

Fig. 1. Integrated flux values for nondiverted PDX discharges measured for various impurities as a function of the radial position of the sample.

(EPPL-803492)

Fig. 2. Profile of impurities deposited onto the Stss sample through the $0.38 \mathrm{~cm}$ defining aperture. Titanium is the limiter material and the observed broadening of the deposition profile relative to the aperture dianeter enables an estimate to be made of the ratio of charge state/energy. The peculiar shape noted in the $c 1$ and $S$ profiles is not believed to be related to finite gyro-radius effects, beaause similarly-shaped profiles have been observed on stainless steel samples exposed to ilydrogen glow discharges whare $\mathrm{B}=$ 0 . Surface diffusion may significantly affect the observed proEiles fo: $\mathrm{Cl}$ and $s: 15]$. 


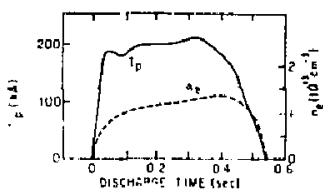

(PPPL-806039)

Fig. 3. Time resolved analysis of edgeplasma fluxes for a non-diverted PDX discharge. The impurity fluxes (O, Ti, CI) are measured by the SAS, the hydrogen flux by the ion velocity analyzer described in [14].
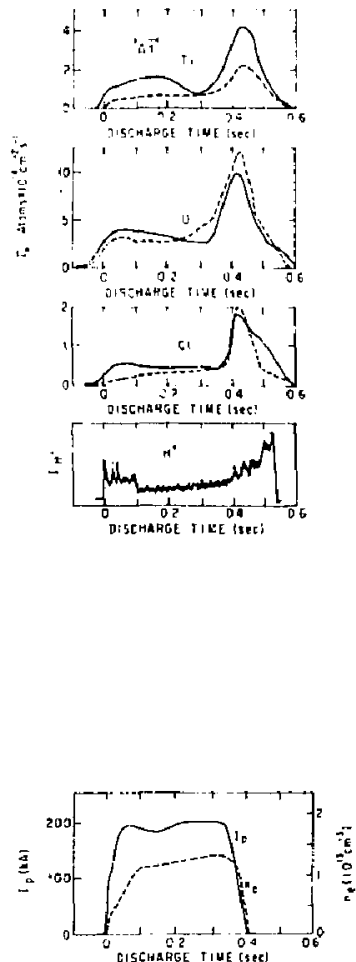

(PPPL-806038)

Fig. 4. Time resolved analysis of the edgeplasma fluxes for a second type of nondiverted PDY discharge.
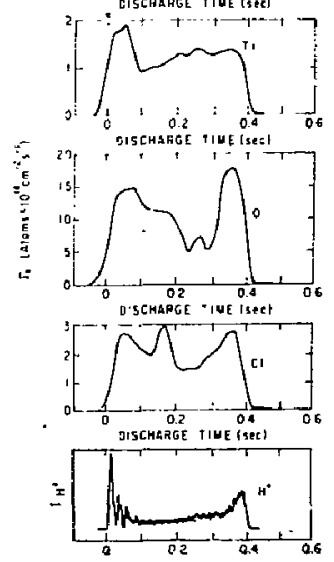